\title{
COMPUTATIONAL INTELLIGENCE FOR ESTIMATING COST OF NEW PRODUCT DEVELOPMENT
}

\author{
Marcin RELICH \\ University of Zielona Gora, Faculty of Economics and Management, Poland \\ e-mail: m.relich@wez.uz.zgora.pl
}

\begin{abstract}
This paper is concerned with estimating cost of various new product development phases with the use of computational intelligence techniques such as neural networks and fuzzy neural system. Companies tend to develop many new products simultaneously and a limited project budget imposes the selection of the most promising new product development projects. The evaluation of new product projects requires cost estimation. The model of cost estimation contains product design, prototype manufacturing and testing, and it is specified in terms of a constraint satisfaction problem. The illustrative example presents comparative analysis of estimating product development cost using computational intelligence techniques and multiple regression model.
\end{abstract}

Keywords: project management, neural networks, fuzzy neural system, constraint satisfaction problem, decision support system.

1

Introduction

Decrease of product life cycles, increase of product variety, and successful adjustment to market trends impose considerable attention to new product development (NPD), which is one of the most important factors in maintaining company's competitiveness. The success of new products depends on customer satisfaction that derives from product utility, quality, and price [1-4]. To incorporate customer requirements in a new product, a company incurs expenditures during the NPD phases such as product design, prototype manufacturing, and testing $[5,6]$.

The research and development ( $R \& D)$ budget is often limited and requires the selection of the most promising NPD projects according to the criteria such as the expected profitability of a new product, product life cycle, and the cost of NPD. As a result, cost estimation of the NPD projects is of special significance in the field of project management.

The cost of NPD can generally be considered from the perspectives such as product design, manufacturing, and testing [7-10]. The product design phase includes design reusability and engineering design. The manufacturing cost is related to the required materials, equipment, and labor to manufacture a prototype that is tested in the next phase. The product design phase is especially important because it precedes other phases. The wrong product design increases cost related to special equipment or modifications, inefficient assembly, excessive part proliferation, difficulties with part fabrication and product reliability, and finally, customer dissatisfaction [11].

Cost estimation of new product development can use the data of past projects that are usually stored in an enterprise information system. This system includes software such as enterprise resource planning (ERP), customer relationship management (CRM), computer-aided design (CAD), computer-aided engineering (CAE), and computer-aided manufacturing (CAM). In the context of a particular product, the use of software for tracking and controlling data is named product data management (PDM). PDM is part of product lifecycle management (PLM) that allows manufacturing companies to manage their products throughout their lifecycles, from the idea generation of a new product, its development and manufacturing, to disposal $[12,13]$. PLM represents connection between $\mathrm{CAD}$, digital manufacturing, and simulation, as well as the virtual world and interfaces with the ERP system supporting the physical side of modern manufacturing along the supply chain $[14,15]$.

The advancement of information technology helps companies manage business processes and use the collected data for acquiring information. Identification of the valid and useful patterns requires the 
use of data mining techniques and a specific approach to specify the data in a uniform form. This study aims to develop a model of cost estimation of new product development in terms of constraint satisfaction problem (CSP) providing a foundation for conceptual analysis. The CSP consists of a set of variables, their domains, and constraints, and it can be considered as a knowledge base enabling the design of a knowledge-based system that includes the identified patterns, expert knowledge, and routine queries such as what is the cost of new product development phases, what is the most promising set of products for development, or what values should have the parameters of a NPD project to fulfil the cost expectations. The proposed approach uses computational intelligence techniques (artificial neural networks and fuzzy neural system) to identify the relationships between the NPD cost and product parameters that are stored in a typical enterprise database. Knowledge base and inference engine of the proposed approach has been developed with the use of constraint programming environment.

The remaining sections of this paper are organized as follows: Section 2 presents a literature review on the new product development process, cost estimation in NPD, and the use of computational intelligence techniques in NPD. Section 3 presents a model of cost estimation of new product development in terms of a constraint satisfaction problem. The proposed method of estimating product cost is presented in Section 4. An example of the proposed approach is illustrated in Section 5. Finally, some concluding remarks are contained in Section 6.

\section{$2 \quad$ Literature review}

\subsection{New product development process}

The new product development literature emphasizes the significant relationship between launching new products and continuing business success $[1,16,17]$. Moreover, new product development from a global perspective influences on technological progress, economic growth, employment, and standard of living [18]. New product development is a crucial process in sustaining a company's competitive position, enabling competitiveness in dynamic markets. However, market competition and product technology advancement is often intense [19], making the new product development a relatively risky activity [20]. As a result, organizations try to meet customer requirements, increase product functionality, and improve the NPD process. To succeed in the contemporary business environment, organizations are forced to more precise identification of customer needs, increase of product quality, and accelerating commercialization of a new product [2]. For this purpose, more and more companies use IT solutions, including rule-oriented decision support systems.

New product development is a complex and timeconsuming process in which a product is designed, manufactured, tested, and finally, launched on the market. Many NPD models have been developed over the years taking into account the abovementioned stages of the NPD process. Sun and Wing [21] present the NPD process in the context of the following phases: idea generation and conceptual design, definition and specification, prototype and development, and commercialization. In turn, Ulrich and Eppinger [9] describe the concept development process, as identification of customer needs, establishment of target specification, concept generation, concept selection, concept testing, establishment of final specification, and product development plan.

The concept selection is the critical phase of the NPD process because it precedes more expensive and long-term phases related to detailed design, manufacturing, testing, and commercialization of a product. The concept selection aims to identify the most promising product portfolio for development, with the use of criteria such as the projected profit and unit cost of a new product, and the estimated total cost of new product development.

\subsection{Cost estimation in new product development}

The main objective of cost estimation in the context of new product development is analysis of projected profitability of a new product and selection of the most promising NPD projects portfolio [22]. Moreover, cost estimation of the NPD phases (especially cost of product manufacturing) facilitates the establishment of the price of a product, its comparison 
with the prices of competitors' products, and determination of price competitiveness of a new product. After selecting the most promising NPD portfolio, cost estimation can be used to prepare the budget of the successive NPD phases: product design, manufacturing, testing, and commercialization, and compare the planned costs with actual operating costs. Cost estimation is also important in the context of preparing the budget for labor, equipment, materials, and components required for product manufacturing [23-25]. Consequently, cost estimation of new product development facilitates the decision maker to answer to the following questions: should the considered product be developed, what cost will be incurred in the specific NPD phases (or company's departments), and what cost is related to labor, assembly, purchased materials, components, etc.

The cost estimation methods in the context of new product development can be divided into two main approaches: variant-based and generative cost estimation [26]. Variant-based cost estimation is related to the similarity between a new product and the previously developed products. In this approach, the cost of the previously developed products is a sample in the cost estimation process of new products. This approach is useful in development of the relatively similar products, for example, in mass customization. In turn the second approach, that is, generative cost estimation is related to the specific cost incurring during the new product development process, for example, in designing product, manufacturing and testing prototype. The use of generative cost estimation is required for the completely new products that are designed from scratch, and a company cannot use the previous cases. As companies usually modify the previous products and do not develop a new product from scratch, these two approaches can be combined to estimate cost of NPD.

The parametric models of estimating cost can be considered from the perspective of the general and specific models. A general model is built to estimate the cost of a product without making reference to any product family. In turn, a specific model is designed for a dedicated product family and it can only estimate the cost of a product that belongs to the same product family [27]. The parametric models of estimating new product can be based on linear regression analysis, nonlinear models, or computational intelligence techniques. Mislick and Nussbaum [28] present cost estimation with the use of multivariable linear regression analysis and multiplicative models (e.g., logarithmic, exponential, and power) that are transformed into linear models. They also consider cost estimation in the context of learning curve analysis (within unit theory and cumulative average theory), wrap rates, and stepdown functions. The description of computational intelligence techniques and their use in the context of new product development is presented in the next subsection.

\subsection{Computational intelligence techniques in new product development}

A nature-inspired methodology of computational intelligence involves adaptive mechanisms, ability to learn, generalization, and pattern discovery. Computational intelligence can improve the capacity of information management systems used in modern designing and manufacturing, for example, through capturing the decision rules of human experts and use these rules to automated decision making [29]. Computational intelligence includes techniques such as artificial neural networks, fuzzy logic, evolutionary algorithms, artificial immune systems, probabilistic reasoning, and multiagent systems. As the connection of different computational intelligence techniques can combine their advantages, many hybrid structures have been developed. For example, the integration of single computational intelligence techniques is reflected in fuzzy neural system, fuzzygenetic system, and fuzzy-neural-genetic system [30].

An artificial neural network with its nonlinear and parallel computing technique is a powerful approach to perform fast and complex computations, and identify nonlinear and complex relationships among data, if there are any [31, 32]. Fuzzy systems are based on fuzzy set theory and imitate the aspect of human cognition that can be called approximate reasoning. Fuzzy terms are not precise but they are meaningful and allow description of real-world situations and reason about them [30]. Fuzzy neural system has the advantages of both neural networks (e.g., 
learning abilities, optimization abilities and connectionist structures) and fuzzy systems (e.g., if-then reasoning, simplicity of incorporating expert knowledge). Artificial neural network and fuzzy neural system are learnt from training samples, and after learning they are able to perform nonlinear predictive modeling, simulation, and forecasting.

In the last years, a wide range of computational intelligence techniques, including artificial neural networks, fuzzy systems, and fuzzy neural systems, has been used in the field of new product development. For example, artificial neural networks have been applied to estimation of production costs [31], prediction of product reliability performance [33], and cost estimation of the product life cycle in conceptual design [34]. Fuzzy logic-based approaches can support the decision makers in estimating market demand for new product development [35], estimating reliability improvement during product development [36], selecting suppliers for new product development [37], evaluating project risk, and status [38-40]. In turn, fuzzy neural systems can be used to create innovative product concepts [41], generate customer satisfaction model [42], or select the most promising NPD portfolio [43].

\section{Model of NPD Cost Estimation in Terms of CSP}

The product development process includes designing, prototyping, testing, and launching a product. Today's information systems (e.g., CRM, CAD, ERP) support the user in managing these phases of the NPD process, and also register and store the performance of the previous NPD projects (e.g., customer requirements, design parameters, product manufacturing). The stored data can be used to identify the key factors influencing cost of a particular phase of the NPD process, and finally, improve the performance of the current NDP projects and the success of a product. Fig. 1 illustrates model of cost estimating for new product development in the context of an enterprise system database.

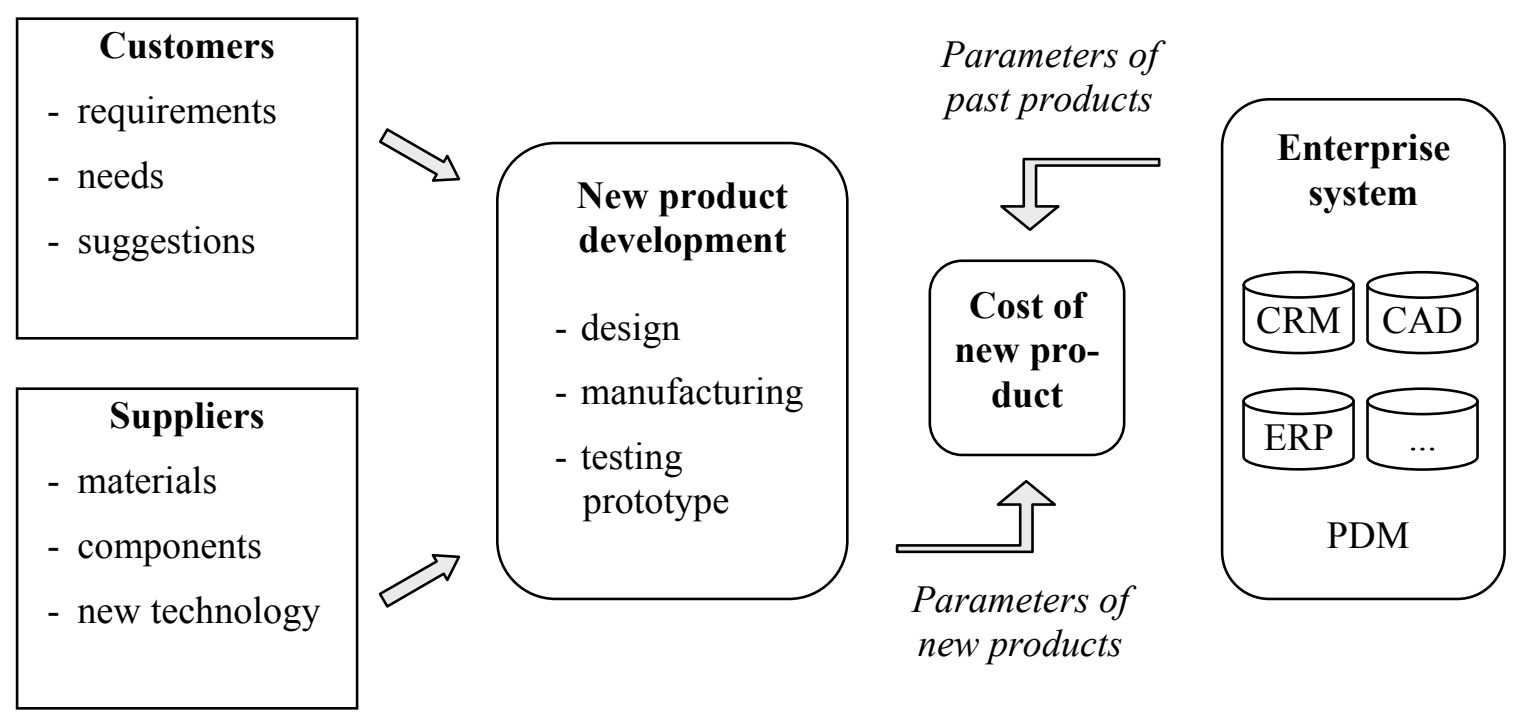

Figure 1. Model of cost estimation for new product development

The presented model can be described as a set of variables, their domains, and the constraints that refer to the company's resources and performance indicators. The model description encompasses the limitations of a company, parameters of products and a set of routine queries that are formulated in the framework of CSP. The structure of the constraint satisfaction problem is described as follows [44]:

$$
\mathrm{CSP}=((\mathrm{V}, \mathrm{D}), \mathrm{C})
$$

where:

- $\mathrm{V}$ is a finite set of variables, 
- $\mathrm{D}$ is a finite set of discrete domains of variables,

- $\mathrm{C}$ is a finite set of constraints limiting and linking variables.

The presented model of new product development consists of three phases: design, manufacturing, and testing the prototype, for which cost estimation is conducted. In the phase of product design, the following variables can be considered:

- number of interviewed clients to survey client's requirements,

- number of client's requirements for a new product,

- number of client's requirements translated into product specification,

- number of ideas for a new product,

- number of components in a new product,

- number of unchanged components in a new product,

- number of project team members.

The cost of manufacturing prototype can depend on the following variables:

- number of components for assembling,

- assembly time,

- assembly machines,

- time for assembly machine configuration,

- number of components for processing,

- processing time.

In the phase of testing prototype, the variables suspected of influencing cost are as follows:

- number of components in a new product,

- number of cycles for testing prototype,

- number of devices for testing prototype,

- number of suppliers for the required materials and components,

- number of new suppliers.

The constraints include the total number of team members directly involved in a NPD project $\mathrm{C}_{1, t}$, the number of machines $\mathrm{C}_{2, \mathrm{t}}$, and financial means $\mathrm{C}_{3, t}$ in the $\mathrm{t}$-th time unit $(\mathrm{t}=0,1, \ldots, \mathrm{T})$. The decision criterion for product portfolio selection is minimization of the total cost of a product by the given constraints.
The constraint satisfaction problem can be considered in the context of a knowledge base that is a platform for query formulation and obtaining answers $[45,46]$. As a knowledge base can be considered in terms of a system, at the input of the system are the variables concerning basic characteristics of an object that are known and given by user [45]. The model formulation in terms of CSP integrates technical parameters, available resources, identified patterns (rules) and user requirements in the form of knowledge base, and facilitates the development of a decision support system [46, 47]. The problem solution is related to seeking the answer to the following questions:

- What is the NPD cost and what products should be selected to the product portfolio to obtain the minimal total cost of NPD projects by a fixed amount of resources?

- What values should have the parameters of NPD projects to fulfil the cost expectations?

The methodology of finding solutions for the abovedescribed problem is presented in the next section.

\section{The Proposed Method for Estimating Product Development Cost}

The enterprise information systems register steadily an enormous amount of data related to the business processes in a company, including performance of the new product development projects. Consequently, the enterprise databases can be used to derive valuable information for improving performance of business processes in an organization. Analysis of huge amount of data and information acquisition using manual methods is slow, expensive, subjective, and prone to errors [48-50]. Data mining techniques are seen as a promising tool to automate the process of seeking hidden relationships among data and retrieving valuable information. Data mining is a stage of the knowledge discovery process and its aim is to identify nontrivial, novel, and potentially useful patterns in data $[51,52]$. In this study, two data mining techniques are considered, that is, neural networks and fuzzy neural networks. 
The proposed method for estimating project development cost consists of the following steps:

- selecting the input variables influencing cost of new product development,

- preprocessing dataset for more efficient use of data mining techniques,

- using data mining techniques to seeking relationships among data,
- determining the range of the input variables for NPD projects,

- estimating cost of new product development,

- conducting sensitivity analysis of cost and selecting optimal NPD project portfolio,

- seeking a set of admissible solutions that fulfil the NPD budget expectations.

Fig. 2 presents the framework of decision support system for the proposed method.

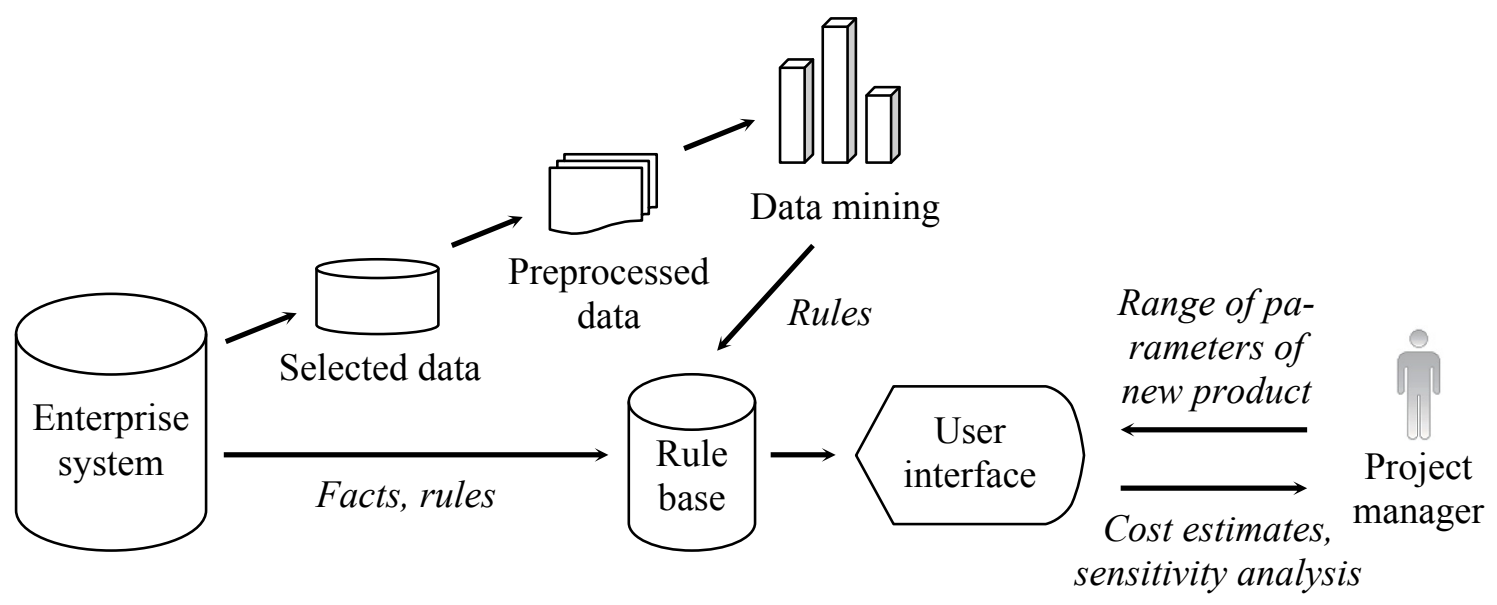

Figure 2. Framework of decision support system for estimating NPD cost

In the first step of the proposed method, the variables suspected of generating cost of new product development are selected. The variables are divided into three groups related to the new product development process: product design, manufacturing and testing prototype. The next step of the proposed method is related to data preprocessing. As the collected variables have different ranges, the data requires transformation in order to use more effectively data mining techniques. The data preprocessing facilitates the improvement of modeling accuracy of artificial neural networks and fuzzy neural networks. In this study, the principal component analysis has been used to transform data before the learning phase of data mining techniques.

The data mining techniques aims to identify the relationships between the cost of a product and the variables that are suspected of influencing cost. This study considers two types of data mining techniques: artificial neural networks (ANN) and fuzzy neural networks (FNN).
In the next step, the project manager determines the range of parameters of new products. These values are the inputs for the learnt ANN and FNN that with the use of the identified relationships estimate the cost in three dimensions: product design, manufacturing prototype, and testing prototype. The total cost of new product development is calculated by adding these three types of cost. If the total cost of NPD projects exceeds the budget expectations, then constraint programming $(\mathrm{CP})$ is used to seek the values of parameters of new products, for which the financial constraint is fulfilled. CP is able to solve constraints satisfaction problems with greatly reduction of the amount of search needed [53]. This is sufficient to solve many practical problems such as supply chain problem or scheduling problem [54 - 57]. The next section presents an illustrative example of comparative analysis of estimating product development cost with the use of computational intelligence techniques and multiple regression model. 


\section{$5 \quad$ Illustrative Example}

An example consists of two parts that are related to two problems (queries) described within the model of cost estimation of new product development. The first part presents the use of computational intelligence techniques (neural networks and fuzzy neural system) to seek relationships that describe the cost of a product development phase and the estimate cost. In turn, the second part shows the use of $\mathrm{CP}$ to seek such values of input variables that fulfil the cost expectations.

\subsection{Cost Estimation and Sensitivity Analysis of New Product Development}

Cost estimation has been carried out with the use of neural networks and fuzzy neural system (the adaptive neuro-fuzzy inference system [ANFIS]) and compared with the linear regression model, and the average of $R \& D$ cost of past products. The NPD cost has been estimated separately for three fields: product designing, prototype manufacturing, and prototype testing. The data has been acquired from an enterprise information system and preprocessed before seeking relationships and forecasting, with the use of the principal component analysis. To eliminate the overtraining of ANN and ANFIS (too strict function adjustment to data) and to increase the forecasting quality, the data set has been divided into learning (P1 - P30) and testing set (P31 - P38). Cost estimation and sensitivity analysis has been carried out with the use of a model that provides the best forecasting quality, i.e. the least root mean square error in the testing set.

In this study, a multilayer feed-forward ANN has been trained according to the back-propagation algorithm and weights optimized according to the Levenberg-Marquardt algorithm (LM) and gradient descent momentum with adaptive learning rate algorithm (GDX). The neural network structure has been determined in an experimental way, by the comparison of learning set (LS) and testing set (TS) for the different number of layers and hidden neurons. The root mean square errors (RMSE) have been calculated as the average of 50 iterations for each structure of a neural network with a number to the extent of 30 hidden neurons. In turn, the ANFIS has been trained according to subtractive clustering method implemented in Matlab ${ }^{\circledR}$ software, with the following parameters: range of influence -0.3 , squash factor -1.25 , accept ratio -0.5 , reject ratio -0.15 .

\subsubsection{Cost of Product Designing}

Cost of product designing (CD) has been estimated on the basis of the following variables: the number of interviewed clients (CS), the number of client's requirements for a new product $(\mathrm{CR})$, the number of client's requirements translated into product specification (CRT), the number of ideas for a new product (INP), the number of components in a new product (CNP), the number of unchanged components in a new product (UCP), and the number of project team members (PTM). Table 1 presents the RMSE for the different estimating models for CD in learning and testing set.

Table 1. Comparison of estimating models for CD

\begin{tabular}{|c|c|c|}
\hline Model & RMSE for LS & RMSE for TS \\
\hline ANN LM & $7 \mathrm{e}-15$ & 7.447 \\
\hline ANN GDX & 7.809 & 9.023 \\
\hline ANFIS & 0.037 & 3.802 \\
\hline Linear regression & 9.551 & 13.702 \\
\hline Average & 19.685 & 27.392 \\
\hline
\end{tabular}


The least RMSE in the testing set has been obtained with the use of the ANFIS that generated 30 rules for the identified relationships. The RMSE of the ANN and ANFIS outperform the results obtained by the average and linear regression model. As the ANFIS obtained the least RMSE, it has been used to estimating cost of the product design phase. The parameters of the considered product are as follows: CS - 128, CR - 22, CRT - 18, INP - 42, CNP
- 55, UCP -43 , and PTM - 4. After inputting these variables to the learnt ANFIS, the cost forecast equals 138 monetary units (m.u.). This information can be used to feasibility study of the NPD projects and selecting the most promising projects for development. Fig. 3 illustrates the membership functions for the first 10 rules used for estimating cost of the product design phase.
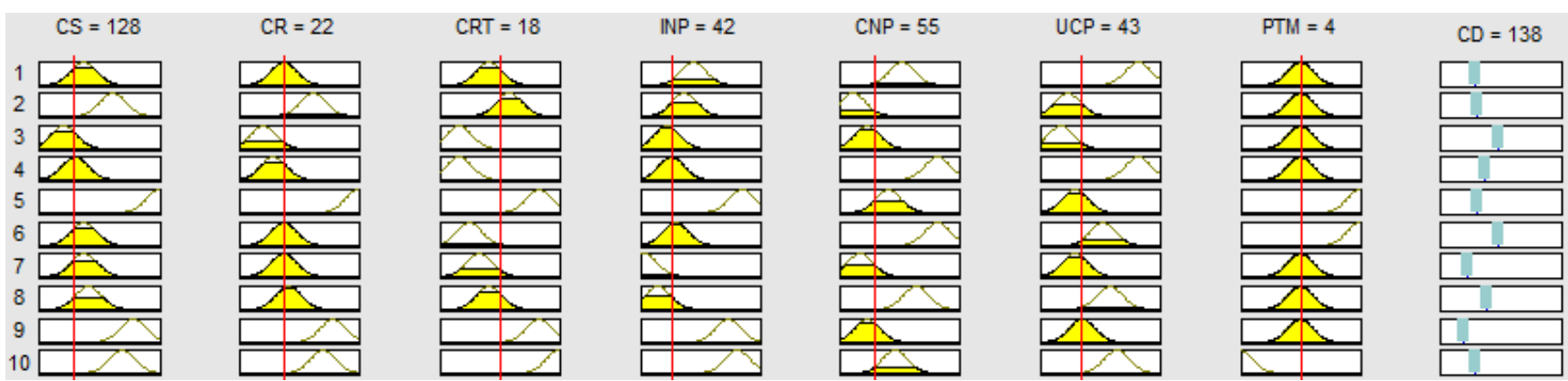

Figure 3. Estimating cost with the use of ANFIS

The cost-effectiveness of the NPD projects can be presented in the form of sensitivity analysis by assigning the range of the planned values of input variables. Fig. 4 presents cost estimates of the product

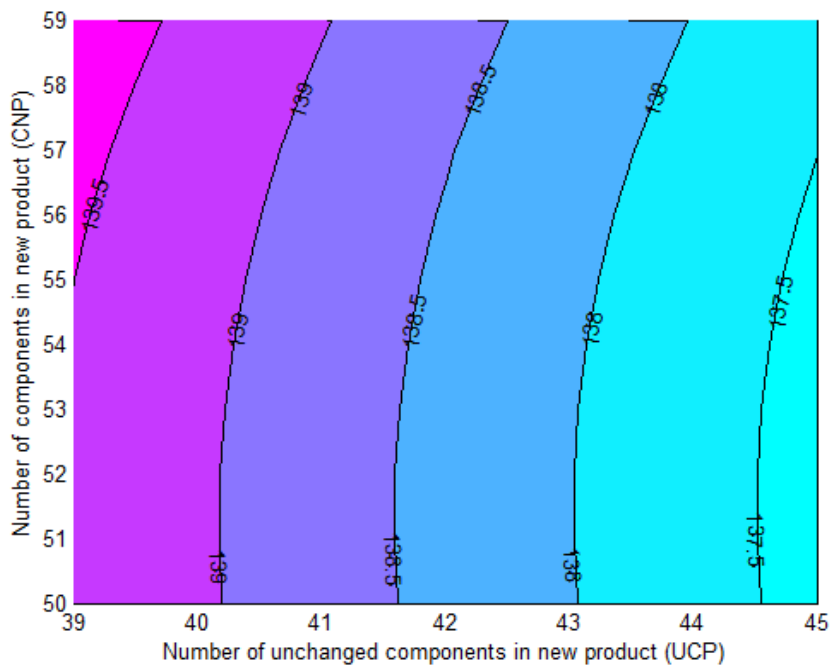

design phase for the number of components in a new product from 50 to 59 , for unchanged components in a new product from 39 to 45 , and for four (on the left) and five (on the right) members of project team.

Figure 4. Contour plot of cost for four and five members of project team

The contour plots shown in Fig. 4 illustrate the strength and direction of cost changes. The increasing number of components in a new product results in cost growth for the range from 53 to 59 components by the relation: the greater number of component the greater increment of cost. In turn,

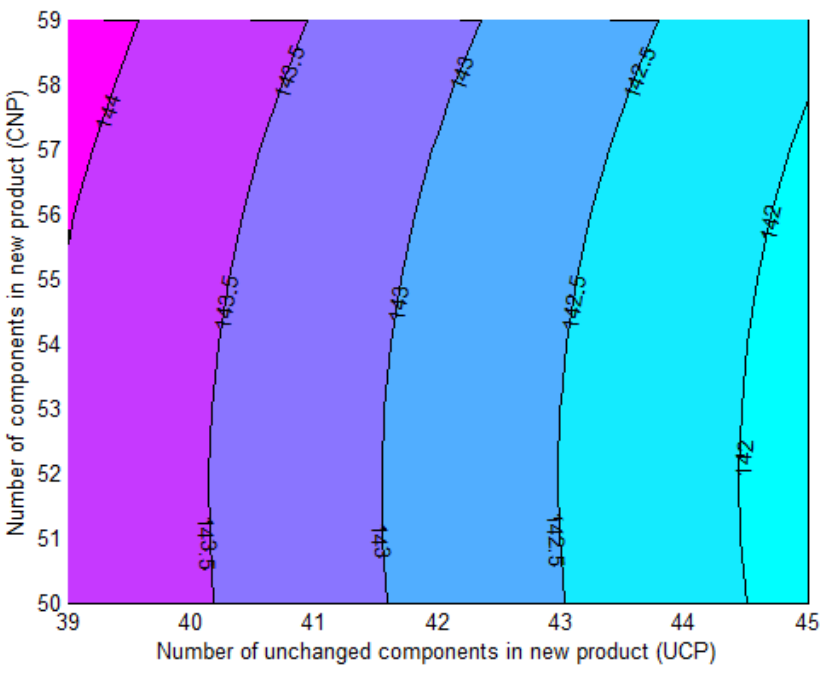

cost is constant in the range $50-53$ components. Moreover, the results indicate the increase of cost (about 4.5 m.u.) for the additional member of project team. The above plots also show the decline of cost for the increasing number of unchanged components in a new product. 
Each additional unchanged component in a new product causes cost savings of $0.3 \mathrm{~m} . \mathrm{u}$.

\subsubsection{Cost of Product Manufacturing}

Cost of product manufacturing (CM) has been estimated with the use of the following input variables: the number of components for assembling (CA), assembly time (AT), assembly machines (AM), time for assembly machine configuration (AMC), the number of components for processing (NCP), and processing time (PT). Table 2 presents the RMSE for the different estimating models for CM in learning and testing set.

Table 2. Comparison of estimating models for $\mathrm{CM}$

\begin{tabular}{|c|c|c|}
\hline Model & RMSE for LS & RMSE for TS \\
\hline ANN LM & $1 \mathrm{e}-15$ & 1.0117 \\
\hline ANN GDX & 0.7537 & 0.7402 \\
\hline ANFIS & 0.0028 & 1.4165 \\
\hline Linear regression & 1.0840 & 1.5965 \\
\hline Average & 2.0025 & 2.7000 \\
\hline
\end{tabular}

The least RMSE in the testing set has been obtained with the use of the ANN GDX for 17 hidden neurons in one hidden layer. Both ANNs and ANFIS have been generated smaller RMSE values than the linear regression model and the average. Cost of the product manufacturing phase has been estimated with the use of the ANN GDX for the following values of input variables: $\mathrm{CA}-20, \mathrm{AT}-27, \mathrm{AM}-3$, AMC $-0.48, \mathrm{NCP}-33, \mathrm{PT}-54$, and it equals 8.23 m.u.

\subsubsection{Cost of Product Testing}

Cost of product testing (CT) has been predicted on the basis of the following variables: the number of components in a new product (CNP), the number of cycles for testing prototype (CTP), the number of devices for testing prototype (DTP), the number of suppliers for the required materials and components (SRM), and the number of new suppliers (NS). Table 3 presents the RMSE for the different estimating models for $\mathrm{CT}$ in the context of learning and testing set.

Table 3. Comparison of estimating models for CT

\begin{tabular}{|c|c|c|}
\hline Model & RMSE for LS & RMSE for TS \\
\hline ANN LM & $3 \mathrm{e}-15$ & 1.9288 \\
\hline ANN GDX & 1.7675 & 1.2787 \\
\hline ANFIS & 0.0420 & 1.6752 \\
\hline Linear regression & 2.1231 & 2.0653 \\
\hline Average & 4.8985 & 8.2207 \\
\hline
\end{tabular}

The least RMSE in the testing set has been obtained with the use of the ANN GDX for 22 hidden neurons in one hidden layer. All the RMSE generated by ANN and ANFIS are less than the average and linear regression model. The cost of the product testing phase has been estimated with the use of the ANN GDX for the following values of input varia- 
bles: CNP - 45, CTP - 300, DTP - 3, SRM - 9, NS -2 , and it equals 41.85 m.u.

Information about cost of the product testing is useful to feasibility study of the NPD projects and selecting the most promising projects for development. The project manager can also be supported throughout sensitivity analysis that presents cost-

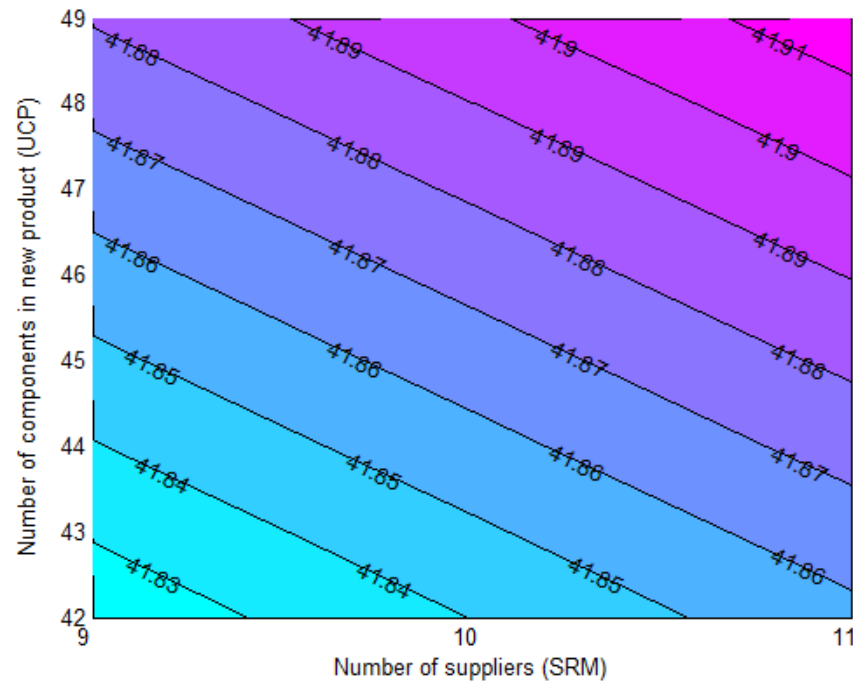

Figure 5. Contour plot of cost for two and three new suppliers

The contour plots illustrate the increase of cost for the increasing number of suppliers and components in a new product. Moreover, the results indicate that the additional new supplier should cause cost savings of 0.08 m.u.

\subsection{Seeking Conditions for Fulfilling Cost Expectations}

The total cost of new product development contains CD, CM and CT, and reaches 188 m.u. If the total cost of NPD exceeds the project budget, the project manager can need information about the conditions to fulfil cost constraint. In this case, such values of input variables are sought that fulfil the cost expectations. Let us assume that the budget of product development is limited to 170 m.u., and the range of the selected variables is as follows: CNP from 40 to 60 , UCP from 25 to 39 , PTM from 3 to 6 , and SRM from 8 to 12. A large number of admissible solutions imposes the use of techniques that enable the reduction of the amount of search needed, such as constraint programming. The considered effectiveness of a NPD project by the different values of input variables.

Fig. 5 presents cost of the product testing phase for the number of components in a new product from 42 to 49 , the number of suppliers for the required materials and components from 9 to 11 , and for two (on the left) and three (on the right) new suppliers.

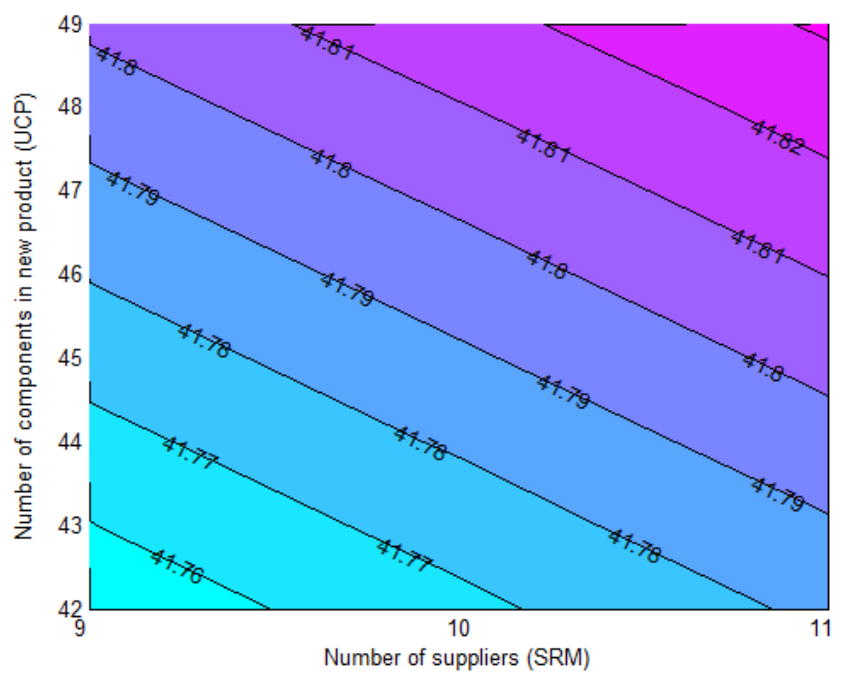


Comparative analysis of cost estimation presents the better forecasting quality for computational intelligence techniques (neural networks and fuzzy neural system) than for multiple regression models. Neural networks have good generalization properties that enable identification of complex relationships among data, if there are any. The more precise estimates of product cost-effectiveness enable selecting the most promising new products for further development, and launch on the market only such products that can compete in prices with competitor's products.

The presented approach identifies the strength and direction of cost changes in relation to the values of variables influencing cost (e.g., the number of suppliers, team members, product components), and in the context of three product development phases: design, manufacturing, and testing. Sensitivity analysis helps the project manager select the optimal parameters in the different phases of a NPD project. Model formulation in terms of a constraint satisfaction problem facilitates data standardization and creation of knowledge base that consists of rules and facts. Knowledge base is used to cost estimating for the expected values of NPD project parameters or/and to seek such values of NPD project parameters that fulfil the budget expectation. In the second case by a large set of admissible solutions, constraint programming is a suitable technique to reduce the time needed to find solutions, if there are any.

Advantages of using the presented approach include cost estimation for the different NDP phases, low effort of data retrieval to analysis (the data are stored in a typical enterprise information system), sensitivity and what-if analysis, and selection of the most promising product portfolio according to the project manager's preferences. Disadvantages of the proposed approach can be considered from the perspective of collecting enough amounts of data of the past similar NPD projects, and specifying several parameters to build and learn a neural network and fuzzy neural system.

\section{$7 \quad$ References}

[1] Cooper R., Edgett S., 2008. Maximizing productivity in product innovation. Research Technology Management, 51(2), pp.47-58.

[2] Chan S.L., Ip W.H., 2011. A dynamic decision support system to predict the value of customer for new product development. Decision Support Systems, Vol. 52, pp.178-188.

[3] Spalek S., 2013. Improving industrial engineering performance through a successful project management office. Engineering Economics, 24(2), pp.88-98.

[4] Relich M., Bzdyra K., 2014. Estimating new product success with the use of intelligent systems. Foundations of Management, 6(2), pp.7-20.

[5] Trott P., 2005. Innovation Management and New Product Development. Essex: Prentice Hall.

[6] Relich M., Bzdyra K., 2015. Knowledge discovery in enterprise databases for forecasting new product success. Intelligent Data Engineering and Automated Learning (ed. K. Jackowski et al.). Lecture Notes in Computer Science, Vol. 9375, Springer, pp.121-129.

[7] Dieter G.E., 2000. Engineering Design: A Material and Processing Approach. Boston: McGraw-Hill.

[8] Nepal B., Monplaisir L., Singh N., 2005. Integrated fuzzy logic-based model for product modularization during concept development phase. International Journal of Production Economics, Vol. 96, pp.157-174.

[9] Ulrich K.T., Eppinger S.D., 2011. Product Design and Development. Boston: McGrawHill.

[10] Relich M., 2015. Identifying relationships between eco-innovation and product success. Technology Management for Sustainable Production and Logistics (ed. P. Golinska, A. Kawa). Berlin Heidelberg: Springer, pp.173192. 
[11] Anderson D.M., 2001. Design for Manufacturability: Optimizing Cost, Quality and Timeto-Market. Cambria: CIM Press.

[12] Sharma A., 2005. Collaborative product innovation: integrating elements of CPI via PLM framework. Computer-Aided Design, Vol. 37, pp.1425-1434.

[13] Danesi F., Gardan N., Gardan Y. Reimeringer M., 2008. P4LM: A methodology for product lifecycle management. Computers in Industry, Vol. 59, pp.304-317.

[14] Alemanni M., Destefanis F., Vezzetti E., 2011. Model-based definition design in the product lifecycle management scenario. International Journal of Advanced Manufacturing Technology, Vol. 52, pp.1-14.

[15] Gola A., Relich M., Kłosowski G., Świć A., 2015. Mathematical models for manufacturing systems capacity planning and expansion - an overview. Applied Mechanics and Materials, Vol. 791, pp.125-131.

[16] Ernst H., 2002. Success factors of new product development: a review of the empirical literature. International Journal of Management Reviews, Vol. 4, pp.1-40.

[17] Kormancova G., 2012. Project success and failure. Theory of Management 6: The Selected Problems for the Development Support of Management Knowledge Base, Zilina, pp.117-119.

[18] Bhuiyan N., 2011. A framework for successful new product development. Journal of Industrial Engineering and Management, Vol. 4, pp.746-770.

[19] McCarthy I.P., Tsinopoulos C., Allen P., Rose-Anderssen C., 2006. New product development as a complex adaptive system of decisions. Journal of Product Innovation Management, Vol. 23, pp.437-456.

[20] Kahraman C., Buyukozkan G., Ates N.Y., 2007. A two phase multi-attribute decisionmaking approach for new product introduction. Information Sciences, Vol. 177, pp.15671582.
[21] Sun H., Wing W., 2005. Critical success factors for new product development in the Hong Kong toy industry. Technovation, Vol. 25, pp.293-303.

[22] Relich M., 2016. A knowledge-based system for new product portfolio selection. New Frontiers in Information and Production Systems Modelling and Analysis (ed. P. Rozewski et al.). Intelligent Systems Reference Library, Vol. 98, Springer, pp.169-187.

[23] Cooper R., Slagmulder R., 1999. Develop profitable new products with target costing. Sloan Management Review, Vol. 40, pp.23-33.

[24] Ben-Arieh D., Qian L., 2003. Activity-based cost management for design and development stage. International Journal of Production Economics, Vol. 83, pp.169-183.

[25] Niazi A., Dai J., Balabani S., Seneviratne L., 2005. Product cost estimation: technique classification and methodology review. Journal of Manufacturing Science and Engineering, Vol. 128, pp.563-575.

[26] Weustink I.F., ten Brinke E., Streppel A.H., Kals H.J., 2000. A generic framework for cost estimation and cost control in product design. Journal of Materials Processing Technology, Vol. 103, pp.141-148.

[27] Foussier P., 2006. From Product Description to Cost: A Practical Approach. London: Springer.

[28] Mislick G., Nussbaum D., 2015. Cost Estimation: Methods and Tools. New Jersay: Wiley $\&$ Sons.

[29] Kusiak A., 2000. Computational Intelligence in Design and Manufacturing. New York: John Wiley \& Sons.

[30] Medsker L., 1995. Hybrid Intelligent Systems. New York: Springer Science.

[31] Cavalieri S., Maccarrone P., Pinto R., 2004. Parametric vs. neural network models for the estimation of production costs: a case study in the automotive industry. International Journal of Production Economics, Vol. 91, pp.165177. 
[32] Relich M., 2010. Assessment of task duration in investment projects. Management, 14(2), pp.136-147.

[33] Lolas S., Olatunbosun O., 2008. Prediction of vehicle reliability performance using artificial neural networks. Expert Systems with Applications, Vol. 34, pp.2360-2369.

[34] Seo K., Park J., Jang D., Wallace D., 2002. Approximate estimation of the product life cycle cost using artificial neural networks in conceptual design. International Journal of Advanced Manufacturing Technology, Vol. 19, pp.461-471.

[35] Aydin R., Kwong C., Ji P., Law H., 2014. Market demand estimation for new product development by using fuzzy modelling and discrete choice analysis. Neurocomputing, Vol. 142, 2014, pp.136-146.

[36] Yadav O., Singh N., Chinnam R., Goel P., 2003. A fuzzy logic based approach to reliability improvement estimation during product development. Reliability Engineering \& System Safety, Vol. 80, pp.63-74.

[37] Carrera D., Mayorga R., 2008. Supply chain management: a modular fuzzy inference system approach in supplier selection for new product development. Journal of Intelligent Manufacturing, Vol. 19, pp.1-12.

[38] Doskocil R., 2016. An evaluation of total project risk based on fuzzy logic. Business: Theory and Practice, 17(1), pp.23-31.

[39] Doskocil R., 2015. Fuzzy logic: an instrument for the evaluation of project status. Revista de Metodos Cuantitativos para la Economia y la Empresa, Vol. 19, pp.5-23.

[40] Relich M., 2013. Fuzzy project scheduling using constraint programming. Applied Computer Science, 9(1), pp.3-16.

[41] Chang D., Chen C., Lee K., 2014. A crowdsourcing development approach based on a neuro-fuzzy network for creating innovative product concepts. Neurocomputing, Vol. 142, pp.60-72.

[42] Kwong C., Wong T., Chan K., 2009. A methodology of generating customer satisfaction models for new product development using a neuro-fuzzy approach. Expert Systems with Applications, Vol. 36, pp.11262-11270.

[43] Relich M., 2015. A computational intelligence approach to predicting new product success. Proceedings of the 11th International Conference on Strategic Management and its Support by Information Systems, Uherske Hradiste, pp.142-150.

[44] Rossi F., van Beek P., Walsh T., 2006. Handbook of Constraint Programming. Elsevier.

[45] Bocewicz G., Nielsen I., Banaszak Z., 2014. Iterative multimodal processes scheduling. Annual Reviews in Control, 38(1), pp.113-132.

[46] Relich M., Swic A., Gola A., 2015. A knowledge-based approach to product concept screening. Distributed Computing \& Artificial Intelligence (ed. S. Omatu et al.). Advances in Intelligent Systems and Computing, Vol. 373, Springer, pp.341-348.

[47] Relich M., Banaszak Z., 2011. Reference model of project prototyping problem. Foundations of Management, 3(1), pp.33-46.

[48] Han J., Kamber M., 2006. Data Mining. Concepts and Techniques. San Francisco: Morgan Kaufmann Publishers.

[49] Cios K.J., Pedrycz W., Swiniarski R.W., Kurgan L.A., 2007. Data Mining: A Knowledge Discovery Approach. New York: Springer.

[50] Relich M., Pawlewski P., 2015. A multi-agent system for selecting portfolio of new product development project. PAAMS 2015 Workshops (ed. J. Bajo et al.). Communications in Computer and Information Science, Vol. 524, Springer, pp.102-114.

[51] Fayyad U., Piatetsky-Shapiro G., Smith P., 1996. From data mining to knowledge discovery in databases. American Association for Artificial Intelligence, Fall, pp.37-54.

[52] Relich M., 2013. Project parameter estimation on the basis of an ERP database. Foundations of Management, 5(2), pp.49-58.

[53] Van Roy P., Haridi S., 2004. Concepts, Techniques and Models of Computer Programming. Massachusetts Institute of Technology. 
[54] Baptiste P., Le Pape C., Nuijten W., 2001. Constraint-Based Scheduling: Applying Constraint Programming to Scheduling Problems. Norwell, Massachusetts: Kluwer Academic Publishers.

[55] Relich M., 2011. CP-based decision support for scheduling. Applied Computer Science, 7(1), pp.7-17.

[56] Banaszak Z., Zaremba M., Muszyński W., 2009. Constraint programming for project- driven manufacturing. International Journal of Production Economics, Vol. 120, pp. 463475.

[57] Relich M., 2014. A constraint programming approach for scheduling in a multi-project environment. International Journal of Advanced Computer Science and Information Technology, 3(2), pp.156-171. 